\title{
Energetical formulation of size effect law for quasi-brittle fracture
}

\author{
Xiaofeng Gao, Georg Koval*, Cyrille Chazallon \\ ICUBE Laboratory, UMR 7357, CNRS, National Institute of Applied Sciences of Strasbourg, 24 Boulevard de la Victoire, 67084 Strasbourg, France
}

\section{A R T I C L E I N F O}

\section{Article history:}

Received 11 May 2016

Received in revised form 2 February 2017

Accepted 3 February 2017

Available online $\operatorname{xxxx}$

\section{Keywords:}

Fracture mechanics

Quasi-brittle rupture

Crack initiation

Crack propagation

\begin{abstract}
A B S T R A C T
A criterion for quasi-brittle failure based on local quantities is proposed. The propagation of long cracks is controlled by the energy release rate, while the initiation of the crack is shown to be well described by the derivative of the energy release rate with respect to the crack length. An equation based on well-known models for the analysis of the size and boundary effects is then adapted to describe the competition between these two quantities in order to characterize the local failure. The predictions of rupture of pre-cracked specimens of different sizes and materials are compared to the experimental results given in the literature. The generality of the formulation for describing the crack propagation mechanisms for other defects, such as v-notches and holes, is finally discussed.
\end{abstract}

(c) 2017 Elsevier Ltd. All rights reserved.

\section{Introduction}

The stress and energy release are basic elements found in most rupture criteria where the failure is characterized by the initiation and propagation of cracks. For an intact structure, a simple stress criterion may indicate crack initiation for a given stress state that is defined as the material strength. On the other hand, considering an energy criterion, a large crack may propagate if the energy release rate during its propagation reaches a certain value associated with the fracture energy of the material. Intermediate situations, such as the rupture of a small cracked specimen or structures presenting "imperfections" other than cracks (e.g. heterogeneities, complex shaped notches, etc.) are not well described by either of these two criteria. These difficulties have given rise to different approaches in order to predict the rupture behavior of quasi-brittle materials.

Based on the stress criteria, Critical Distance Theories (CDTs) were initially proposed in the 1930s by Neuber [1] and Peterson [2] using a punctual evaluation of the stress at a certain distance from the crack tip (Point Stress Method) and the average of the stress over a certain length (Average Stress Method), respectively, in order to analyze the fatigue failure of metallic structures. Adopting the same concept, Novozhilov [3] proposed a simple failure criterion based on the average normal stress along the anticipated path of the crack formation. This model has been expanded by Seweryn [4-7] to study both regular and singular stress concentrations under mode I or mixed mode loading.

Leguillon [8] proposed a criterion for failure initiation at a sharp v-notch under mode I loading, which requires the stress condition and energy condition to be fulfilled simultaneously. This criterion was compared with several known failure initiation criteria and validated in [8,9] for mode I loading. It was improved by Leguillon and Yosibash [10] by introducing a correction due to the small notch tip radius, later extended by Yosibash et al. [11] to mixed mode loading and validated

\footnotetext{
* Corresponding author.

E-mail address: georg.koval@insa-strasbourg.fr (G. Koval).
} 


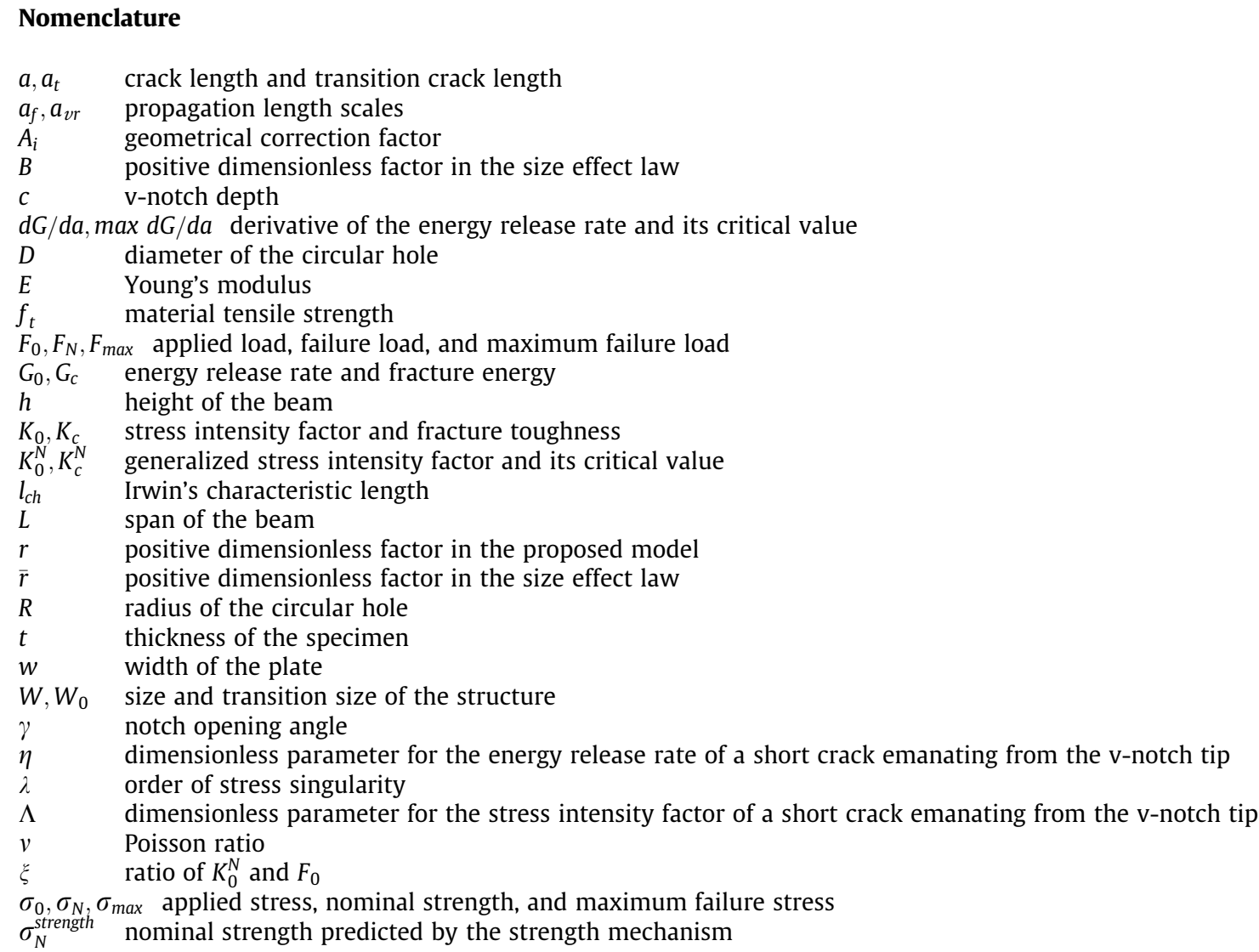

by experimental observations. The concept of Finite Fracture Mechanics was used in Leguillon's criterion, which assumes the instantaneous formation of cracks of finite size at initiation [12]. Instead of the point-wise stress criterion adopted in Leguillon's criterion, Cornetti et al. [13] proposed a similar criterion, based on the evaluation of stresses prior to fracture averaged over the crack. These coupled criterion allows for the general analysis of arbitrary stress concentrations [14-16], and has been used by many researchers to establish general failure criteria for a wide range of engineering problems in the last 14 years [12].

The cohesive zone models [17-19] simulate the damage that occurs in the process zone located ahead of the crack tip. This approach, which involves nonlinear constitutive laws that are described by a displacement jump and corresponding traction along the interfaces, provides a phenomenological model with which to simulate complex fracture behavior, such as crack nucleation, initiation and propagation [20]. The extension of the classical cohesive model to quasi-brittle materials usually shows fractal patterns in the failure process. This fractal approach leads to a scale-invariant cohesive crack model which is able to predict the size effects even in tests where the classical approach fails, e.g. the direct tension test [21].

Most of the methods are associated with a length scale that is usually proportional to Irwin's [22] characteristic length $l_{c h}$, which depends on the properties of the material, such as the stiffness, strength and fracture toughness. However, for certain building materials (such as concrete, rocks, and some types of ceramics), the value of the characteristic length scale can become too large when compared to the specimen size, and sometimes can even exceed it, which makes the direct implementation of these approaches impossible [23]. In the discrete element methods, the materials are organized into assemblies of particles in contact. Initially developed by Cundall and Strack [24] for modelling granular and particulate systems, these methods were further adapted to study the fracture of quasi-brittle materials, such as concrete [25,26] and rocks [27]. Despite the simple (and physical) local point of view of ruptures, the intrinsic scale effects related to the particle size and characteristic length $l_{c h}$ ) also affect the response of the model to quasi-brittle rupture [28-30].

This paper presents an alternative description of quasi-brittle failure based only on local quantities that are related to the energy release rate $G$. Hence, the size [31,32] and boundary effects [33-35] that are observed in the experiments are simply analyzed through the combination of mechanisms related to the strength and fracture toughness of the material, thereby avoiding some of the nonphysical aspects associated with most of the existing models. In Section 2, the notions of the size and boundary effects are presented. Based on the existing expressions used to describe these types of experimental evidence, 
the two local quantities are related, which gives rise to the model presented in Section 3. Section 4 presents a comparison of the model with the experimental results in the literature in the opening mode of various cracks: cracked three-point bending beams, v-notched tensile and bending samples, and plates with a circular hole in tension. Finally, the conclusions and perspectives of the present work are presented.

\section{Size and boundary effects in quasi-brittle rupture}

On a small scale, quasi-brittle materials obey the strength theory that is characterized by the material strength $f_{t}$, while on a large scale, they conform to Linear Elastic Fracture Mechanics (LEFM) and are characterized by the fracture energy $G_{c}$. The combination of $f_{t}$ and $G_{c}$ yields Irwin's [22] characteristic length $l_{c h}=G_{c} E / f_{t}^{2}$, where $E$ is the Young's modulus, and divides the small and large scales [32]. Based on an approximate energy release analysis, the following Type 2 Size Effect Law (SEL) was derived [31] for structures that fail after large stable crack growth (like in Fig. 1a):

$$
\sigma_{N}=B f_{t}\left[1+\left(\frac{W}{W_{0}}\right)^{\bar{r}}\right]^{-1 / 2 \bar{r}},
$$

where $\sigma_{N}$ is the nominal strength, $\bar{r}$ and $B$ are positive dimensionless factors ( $B$ depends on the geometry of the structure), $W$ represents the size of the structure, and $W_{0}$ is the transition size at which the failure laws based on the material strength and LEFM intersect, as shown in Fig. 1b.

Hu and Wittmann [33-35] investigated the size effect on the fracture properties of a large plate with a finite crack (Fig. 1c) and proposed an adaptation of Eq. (1) to describe the dependence of the specimen strength $\sigma_{N}$ on the crack length a:

$$
\sigma_{N}=f_{t}\left[1+\left(\frac{a}{a_{t}}\right)\right]^{-1 / 2}
$$

(a)
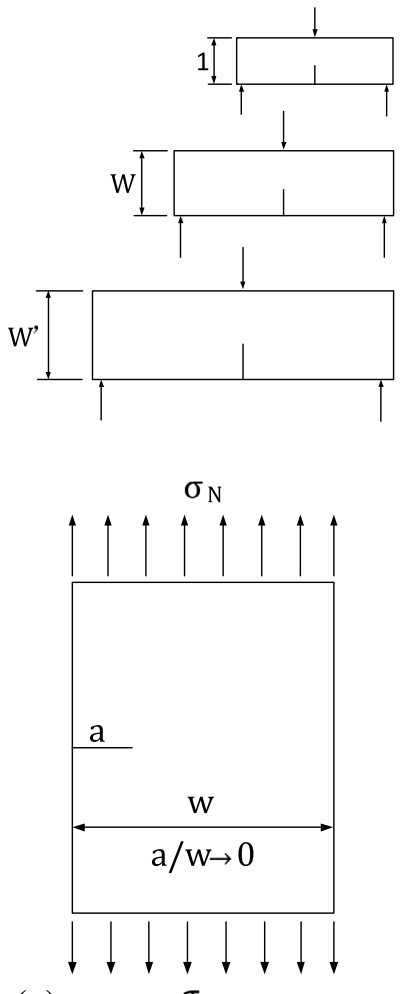

(c)
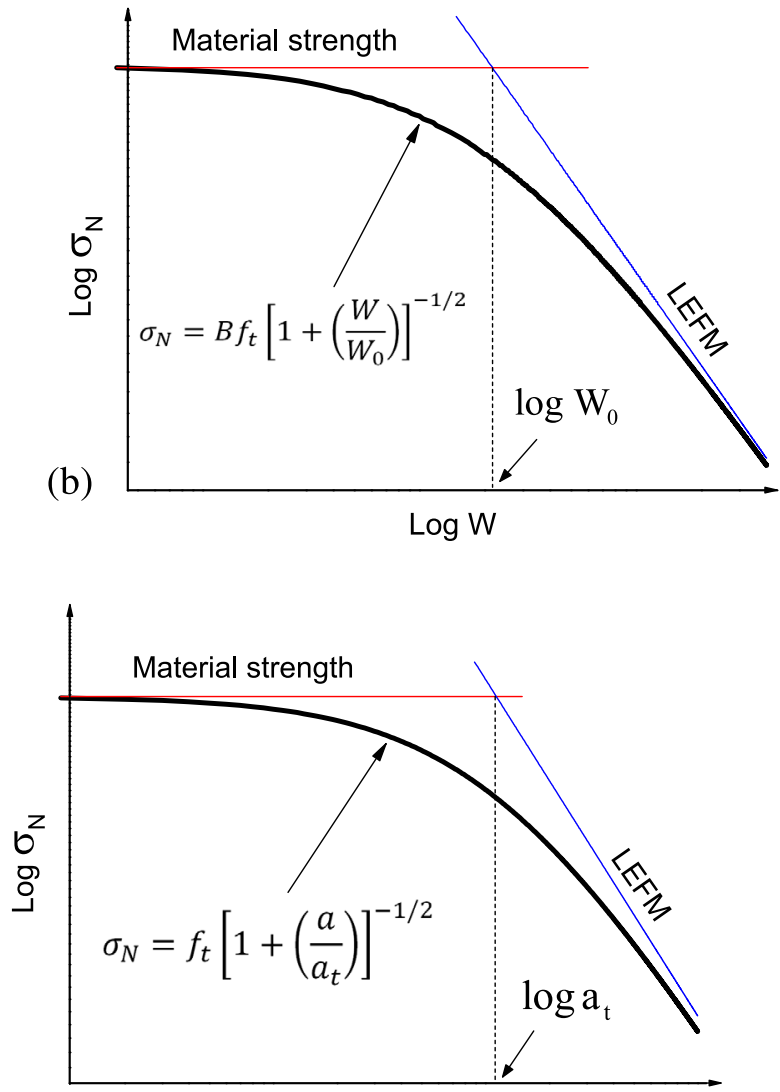

(d) $\log a$

Fig. 1. (a) Similar cracked structures, (b) the size effect law linking the failure mechanisms of the material strength and LEFM (modified from [32]), (c) a crack in a large plate, and (d) its nominal strength $\sigma_{N}$ as a function of the crack length $a$ (modified from [35]). 
where $a_{t}$ is defined by the intersection of the maximum tensile stress and the LEFM criteria, and is referred to as the transition crack size $a_{t}=l_{c h} /\left[A_{1}^{2}(a / w) \pi\right]$, where $A_{1}$ is a coefficient that depends on the geometry of the sample and size of the crack $a$ (for an infinite plate, $A_{1}(a / w \rightarrow 0)=1.12$ [35]). In the case of the large plate, the crack size $a$ represents the distance from the crack-tip to the front free surface of the specimen. Eq. (2) indicates that when the distance of the crack-tip to the front boundary is comparable to $a_{t}$, the specimen strength will experience the boundary effect. When the crack-tip is very far away from the front boundary, the LEFM criterion prevails and the specimen strength will be determined primarily by its fracture energy $G_{c}$ (see Fig. 1d) [35].

Both equations allow the prediction of a failure of a structure while taking into account the size and boundary effects based on the nominal strength $\sigma_{N}$ (a non-local quantity) and structural information, such as the crack size $a$. In the next section, a generalization of Eq. (2) is proposed that is only based on the material parameters and local quantities.

\section{Local approach}

\subsection{Model}

A more general form of Eq. (2) can be used to provide a more concise representation of the failure behavior:

$$
\sigma_{N}=f_{t}\left[1+\left(\frac{a}{a_{t}}\right)^{r}\right]^{-1 / 2 r},
$$

where $r$ is a parameter that describes the transition between a failure that is defined by the material strength $(a \rightarrow 0)$ and one defined by LEFM $\left(a \gg a_{t}\right)$. The effect of this parameter is presented in Fig. $2 \mathrm{a}$ and traduces some complex consequences of the microstructure of the material such as granulometry and voids. Lower values of $r$ lead to smoother transitions between the two mechanisms, which are related to lower rupture values for cracked structures. As shown in detail in Appendix A, the rupture of a quasi-brittle material (represented by Eq. (3)) can be rewritten as the contribution of the two mechanisms:

$$
\left(\frac{\sigma_{N}}{f_{t}}\right)^{2 r}+\left(\frac{G}{G_{c}}\right)^{r}=1
$$

The ratio $\sigma_{N} / f_{t}$ denotes the activation of the material strength, while $G / G_{c}$ is related to the fracture mechanics.

The non-local quantity $\left(\sigma_{N} / f_{t}\right)^{2}$ can be estimated by the ratio between the derivative of the energy release rate with respect to the crack length $d G / d a$ and its maximum value $\max d G / d a$, as discussed in Appendix B. Then, the failure criterion (Eq. (4)) may be finally rewritten as

$$
\left(\frac{d G / d a}{\max d G / d a}\right)^{r}+\left(\frac{G}{G_{c}}\right)^{r}=1
$$

which is a function of quantities obtained exclusively at the crack tip and the parameters of the material. The value of max $d G / d a$ can be obtained experimentally from a sample without cracks or simply determined based on the tensile strength $f_{t}$ and Young's modulus $E$ of the material: $\max d G / d a=\left(1.12 f_{t}\right)^{2} \pi / E$ (see Appendix B).

The values of $[(d G / d a) /(\max d G / d a)]^{r}$ and $\left(G / G_{c}\right)^{r}$ depend on the crack size, as shown in Fig. $2 \mathrm{~b}$. The ratio $[(d G / d a) /(\max d G / d a)]^{r}$ dominates the failure behavior for very small cracks $(a \rightarrow 0)$, which is in the region where fracture mechanics is not adapted for quasi-brittle materials; however its effects diminish for longer cracks. By definition, Eq. (5) predicts the initiation of a crack under nominal stresses reaching the tensile strength $f_{t}$ and crack propagation $G=G_{c}$ for long cracks. The transition between these two mechanisms occurs at $a=a_{t}$, which is the transition crack size.
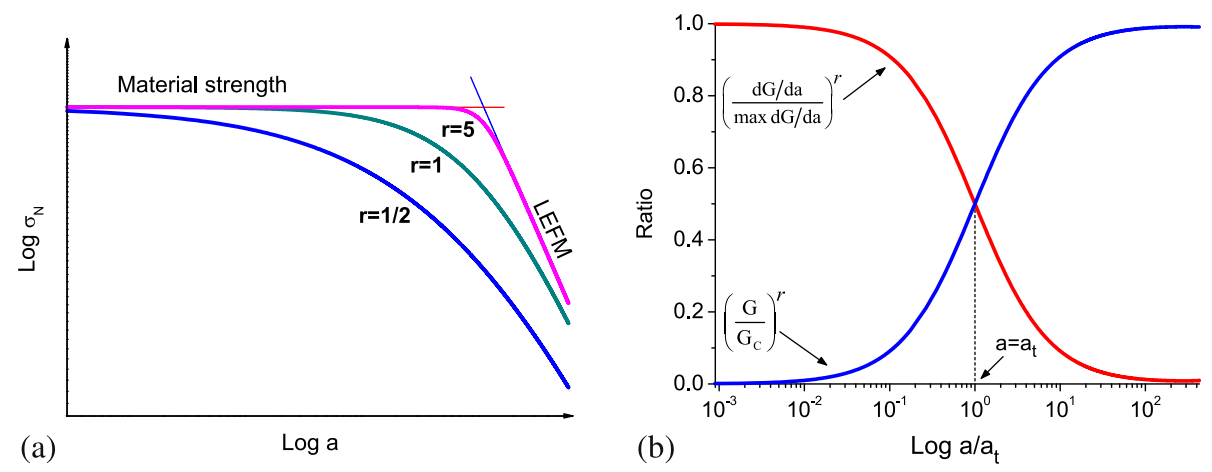

Fig. 2. (a) Nominal strength $\sigma_{N}$ as a function of crack length $a$ for different $r$, and (b) evolution of the ratios $\left(G / G_{c}\right)^{r}$ and $[(d G / d a) /(m a x d G / d a)]^{r}$ as functions of the crack length $a / a_{t}(r=1)$. 
The main advantage of Eq. (5) is that it is independent of geometrical parameters. The values of $G$ and its derivative $d G / d a$ can be quantified for defects that induce stress singularities, such as cracks or v-notches, or do not induce stress singularities, such as holes, as shown in Section 4.

\subsection{Failure load for elastic structures and finite length}

The relation represented by Eq. (5) is defined for a failure load $F_{N}$. If a different load $F_{0}$ is applied, the equation becomes

$$
\left(\frac{d G_{0} / d a}{\max d G / d a}\right)^{r}+\left(\frac{G_{0}}{G_{c}}\right)^{r}=\mu_{0}
$$

where $G_{0}$ and $d G_{0} / d a$ are the corresponding energy release rate and its derivative at the crack tip under the loading $F_{0}$. Considering that $F_{0}$ is a fraction of the failure loading $\left(F_{N}=\rho F_{0}\right)$, by linearity, $G=\rho^{2} G_{0}$ and $d G / d a=\rho^{2} d G_{0} / d a$. The value of $\rho=\mu_{0}^{-1 /(2 r)}$ can be obtained by substituting the relation for $G, d G / d a$, and Eq. (6) into Eq. (5). Finally, the failure load $F_{N}$ can be calculated based on the results of any given load $F_{0}$ based on the expression

$$
F_{N}=\mu_{0}^{-1 /(2 r)} F_{0} .
$$

\section{Comparison to experimental results from the literature}

The failure criterion proposed in Eq. (5) was compared to the experimental results given in the following section. The tensile strength $f_{t}$ and fracture energy $G_{c}$ adopted in the predictions are associated to measured values. However, the parameter $r$ is adjusted in order to minimize the error between predictions and experimental results. The size and boundary effects were clearly visible on the three-point bending tests presented first. The generality of the proposed formulation was then analyzed using the results of the rupture tests of v-notched samples in different configurations. Finally, the crack initiation under a local stress gradient was verified in the tensile tests of samples with circular holes of different sizes.

\subsection{Cracked Three-point Bending (C-TPB) tests}

\subsubsection{Evaluation of $G$ and $d G / d a$}

The stress intensity factor $K_{0}$ of the C-TPB specimen can be directly calculated by

$$
K_{0}=\frac{3 F_{0} L}{2 h^{2} t} \sqrt{\pi a} A_{2},
$$

where $F_{0}$ is the applied load, $L, h$, and $t$ are the span, height, and thickness of the beam respectively, and $a$ is the crack length (see Fig. 3a). The empirical formula for the correction factor $A_{2}$ was derived by Tada [36] for any crack to height ratio $a / h$ :

$$
A_{2}=\sqrt{\frac{2 h}{\pi a} \tan \frac{\pi a}{2 h}} \frac{0.923+0.199\left(1-\sin \frac{\pi a}{2 h}\right)^{4}}{\cos \frac{\pi a}{2 h}} .
$$

The value of the energy release rate was obtained from the LEFM relation for plane stress $G_{0}=K_{0}^{2} / E$, and $d G_{0} / d a$ was calculated by deriving $G_{0}$ with respect to the crack size $a$. These values are related to the material fracture energy $G_{c}$ and material strength $f_{t}$, as shown in Section 3.2, and characterize the failure of the structure.
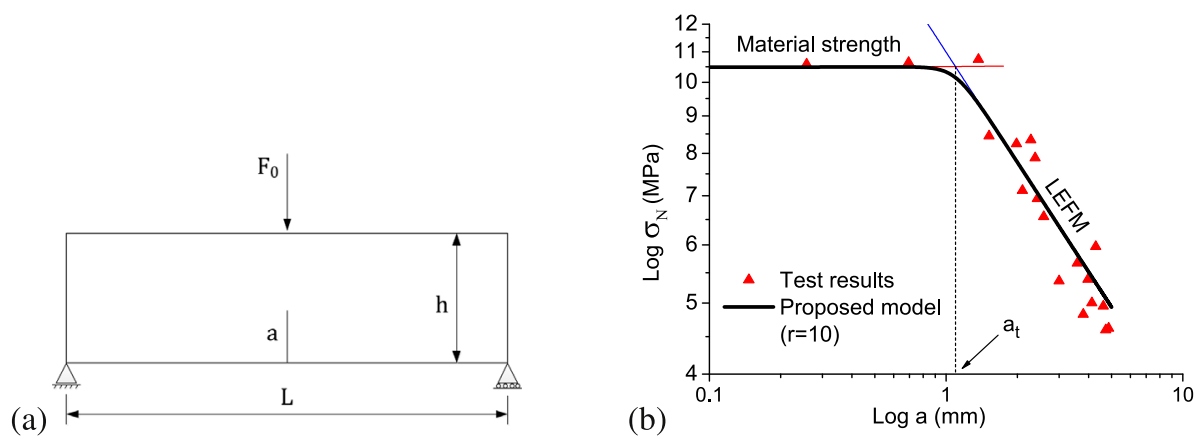

Fig. 3. (a) Three-point bending geometry and (b) the nominal strength $\sigma_{N}$ versus the crack length $a$ for C-TPB specimens [37]. 


\subsubsection{Birchall's experiments}

Fig. 3b illustrates the nominal strength results $\left(\sigma_{N}=1.5 F_{N} L /\left(h^{2} t\right)\right)$ predicted by the proposed model and compared to the test results of the C-TPB specimens tested by Birchall et al. [37] that had a span to height ratio of $L / h=4$ and were made of Portland cement paste. In the figure, the model results were obtained for a beam with dimensions of $h=1 \mathrm{~m}, t=1 \mathrm{~m}$, and $L=4 \mathrm{~m}$. The material parameters were measured by Birchall et al. [37]. The mean tensile strength $f_{t}=10.5 \mathrm{MPa}$ and mean fracture energy $G_{c}=23.8 \mathrm{~N} / \mathrm{m}$ were calculated by measuring the failure loads of uncracked and cracked specimens, respectively, which resulted in a transition crack size of $a_{t}=1.1 \mathrm{~mm}$. The transition between the failure mechanism associated with the material strength and that due to the fracture mechanics (visible in Fig. 3b) is quite sharply delineated, which is well described by a high value of the parameter $r(r=10$ in this case).

\subsubsection{Karihaloo's experiments}

The C-TPB tests performed by Karihaloo et al. [38] were conducted on cracked beams made of hardened cement paste with a span to height ratio of $L / h=4$. The crack to height ratios $a / h$ of the specimens were $0.1,0.3$, and 0.5 , and four beams were tested for each value. The heights of the beams were $50 \mathrm{~mm}, 100 \mathrm{~mm}$, and $200 \mathrm{~mm}$, and all had the same thickness of $100 \mathrm{~mm}$ ). The mechanical properties of the material were measured on several specimens using standard procedures. The mean values of the tensile strength and Young's modulus were $f_{t}=3.53 \mathrm{MPa}$ and $E=20.8 \mathrm{GPa}$, respectively. The value of the fracture energy $G_{c}=13.5 \mathrm{~N} / \mathrm{m}$ was calculated using Eq. (8) based on the measured failure load of the largest specimen (with a height of $200 \mathrm{~mm}$ ), which resulted in a transition crack size of $a_{t}=5.72 \mathrm{~mm}$.

The predicted failure loads given by the proposed model and Bažant's Type 2 Size Effect Law (Eq. (1)), and test results are plotted in Fig. 4a as a function of the crack to height ratio $a / h$. In these example, the value of $r=1$ seems adequate, which indicates a smooth transition between the mechanisms of failure based on fracture mechanics and material strength. This parameter is important considering the range of crack sizes $a(5 \mathrm{~mm}<a<100 \mathrm{~mm})$. The model parameters of Type 2 SEL $G_{c}=18.1 \mathrm{~N} / \mathrm{m}$ and the length scale $c_{f}=7.2 \mathrm{~mm}$ were calibrated for $a / h=0.3$ [39]. $B f_{t}$ and transition size $W_{0}$ in Eq. (1) are calculated respectively for each crack to height ratio based on the given fracture energy $G_{c}$ and length scale parameter $c_{f}$.

\subsubsection{Higgins' experiments}

Higgins and Bailey [40] tested C-TPB specimens of a hardened cement paste with heights $h$ that varied from $5 \mathrm{~mm}$ to $110 \mathrm{~mm}$, and a crack to height ratio $a / h$ that varied from 0.02 to 0.5 . The span to height ratio was equal to $L / h=5$ for all beams, and the thickness was equal to $t=25 \mathrm{~mm}$. Fig. $4 \mathrm{~b}$ shows the comparison between the test results and the predicted failure loads obtained by the proposed model and by the Boundary Effect Model (BEM) [35] as functions of the crack to height ratio $a / h$. The proposed model and boundary effect model are both able to characterize size and boundary effects in this example. The mechanical properties obtained by optimizing the rupture model (for $r=0.5$ ) were: tensile strength $f_{t}=12 \mathrm{MPa}$ and fracture toughness $\sqrt{G_{c} E}=0.83 \mathrm{MPa} \sqrt{\mathrm{m}}$ (the Young's modulus $E$ was not provided), resulting in a transition crack size $a_{t}=1.21 \mathrm{~mm}$. These results are consistent with the values obtained by the authors. The highest value of strength obtained in direct tensile tests on uncracked specimens was $12.5 \mathrm{MPa}$, associated with an estimated fracture toughness of $0.8 \mathrm{MPa} \sqrt{\mathrm{m}}$. The material parameters adopted by Duan et al. [35] in BEM model were: tensile strength $f_{t}=10.29 \mathrm{MPa}$ and fracture toughness $K_{c}=0.65 \mathrm{MPa} \sqrt{\mathrm{m}}$.

\subsection{V-Notched tests}

The results for the failure of the C-TPB specimens (Section 4.1) indicates the ability of Eq. (5) to locally characterize the strength of structures displaying cracks of different sizes. In the following section, the failure of structures associated with
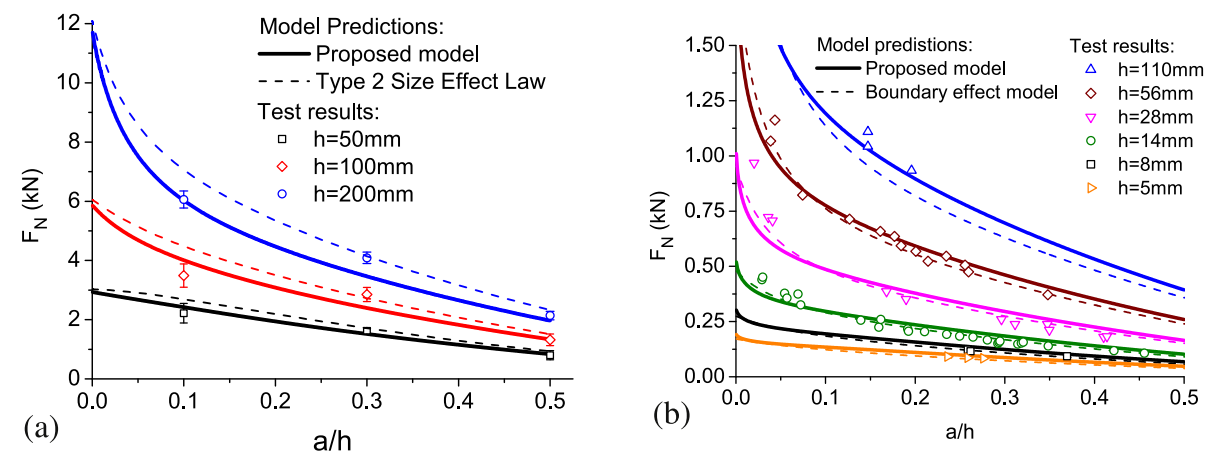

Fig. 4. Failure loads $F_{N}$ versus crack to height ratio $a / h$ for various specimen sizes in the experiments of (a) Karihaloo et al. [38], and (b) Higgins and Bailey [40]. The error bars in (a) indicate the standard deviations of the experimental results. 
other imperfections that induce singular stresses is analyzed. Samples with v-notches, as in Fig. 5, are used as a reference due the dependence of the stress field on the opening angle.

\subsubsection{Evaluation of $G$ and $d G / d a$}

The vertical stress along the $x$-axis (see Fig. 5) in the vicinity of the notch tip can be expressed as $\sigma_{y}(x)=\left(K_{0}^{N}\right) /(2 \pi x)^{1-\lambda}$ [14], where $\lambda$ is the order of the stress singularity, which depends on the notch opening angle $\gamma \cdot \lambda$ is equal to $1 / 2$ for $\gamma=0^{\circ}$ (crack) and 1 for $\gamma=\pi$ (straight edge), and $K_{0}^{N}$ is the Generalized Stress Intensity Factor (GSIF) whose physical dimensions depend on the notch opening angle $\gamma$.

In mode I, the value of the energy release rate for a short crack emanating from the v-notch tip subjected to a given load $F_{0}$ can be written as

$$
G_{0}=\eta \frac{\left(K_{0}^{N}\right)^{2}}{E^{*}} a^{2 \lambda-1},
$$

where $\eta$ is a dimensionless parameter that depends only on the notch opening angle $\gamma$ [41]; in plane stress $E^{*}=E$ and plane strain $E^{*}=E /\left(1-v^{2}\right)$. The value of $d G_{0} / d a=\eta(2 \lambda-1)\left(K_{0}^{N}\right)^{2} a^{2 \lambda-2} / E^{*}$ is obtained by derivation of Eq. (10) with respect to the emanated crack length $a$. The values of $\lambda, \eta$, and $K_{0}^{N}$ are presented in Appendix C for v-notched plates and beams.

\subsubsection{Failure identification}

At the notch tip $(a \rightarrow 0)$, the value of the energy release rate $G_{0}$ tends to zero for any singularity weaker than a crack $(1 / 2<\lambda<1)$ [12], as indicated by Eq. (10), while its derivative $d G_{0} / d a$ tends to infinity. According to Eqs. (6) and (7), in these conditions, the failure load $F_{N}$ tends to zero, as shown in Fig. 6a. The propagation of the crack induces an increase of $G_{0}$ and a decrease of $d G_{0} / d a$, which leads to the rapid growth of the $F_{N}$ value. For very short propagation lengths, the rupture is dominated by the strength mechanism $\sigma_{N}^{\text {strength }}=\sigma_{0} \sqrt{\operatorname{maxdG} / d a /\left(d G_{0} / d a\right)}$, as shown in Fig. $6 \mathrm{~b}$. After a certain length, the fracture toughness of the material is mobilized and the rupture behavior follows the prediction of the LEFM, and depends only on the energy release rate. During the transition between the two mechanisms, a maximum value of the failure load $F_{\max }$ is observed, which defines the failure limit of the sample.

\subsubsection{Seweryn's experiments}

Seweryn et al. [6] carried out tensile experiments using symmetric v-notched polymethyl methacrylate (PMMA) specimens with the following mechanical properties: Young's modulus $E=3.3 \mathrm{GPa}$, Poisson ratio $v=0.35$, tensile strength $f_{t}=102.8 \mathrm{MPa}$, and plane stress fracture energy $G_{c}=437.82 \mathrm{~N} / \mathrm{m}$. The fracture energy $G_{c}$ was calculated by Seweryn et al. based on the relation between the fracture toughness and critical generalized stress intensity factor $K_{c}^{N}$ for notch opening angles $\gamma=20^{\circ}, 40^{\circ}$, and $60^{\circ}$ [7]. Samples with v-notch opening angles $\gamma$ of $20^{\circ}, 40^{\circ}, 60^{\circ}, 80^{\circ}$, and $100^{\circ}$ were studied, and their dimensions are indicated in Fig. 7a with a thickness of $5 \mathrm{~mm}$. The results for $\gamma=180^{\circ}$ were based on the tensile strength $f_{t}$ as determined with a sample presenting a double semicircular indentation.

The predicted failure loads $F_{\max }$ with different notch opening angles are compared to the experimental results in Fig. 7b. A more detailed description of the behavior between $100^{\circ}<\gamma<180^{\circ}$ is provided by the predictions of the strain energy
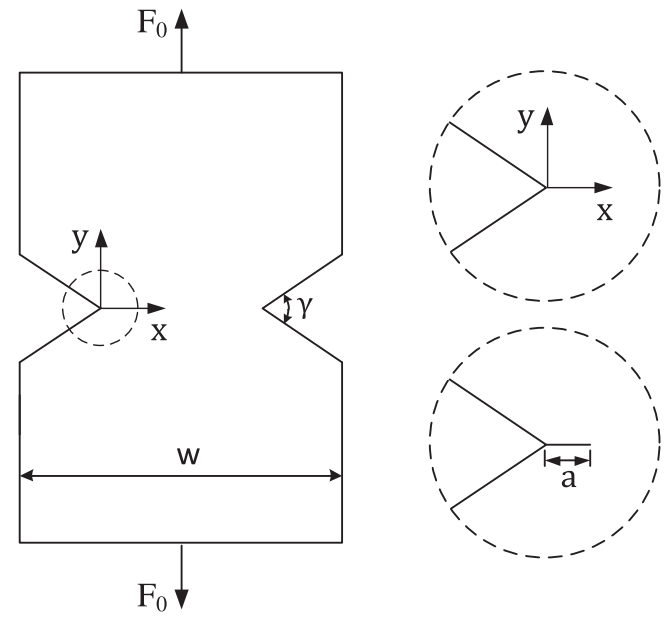

Fig. 5. V-notched plate under tension loading and the corresponding emanating crack. 

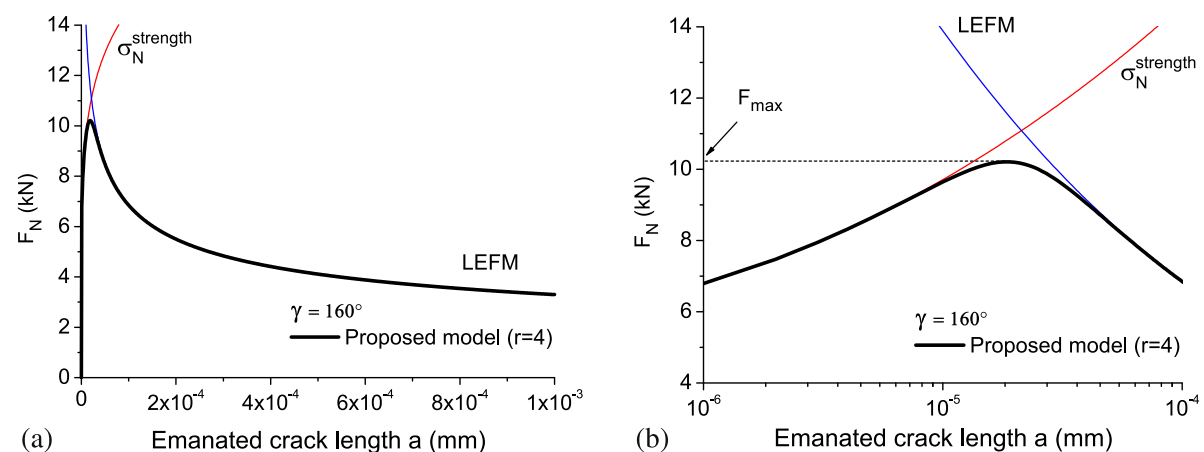

Fig. 6. Failure load $F_{N}$ during crack extension and the definition of the maximum failure load $F_{\max }$ for v-notches in (a) linear, and (b) semi-log scales.
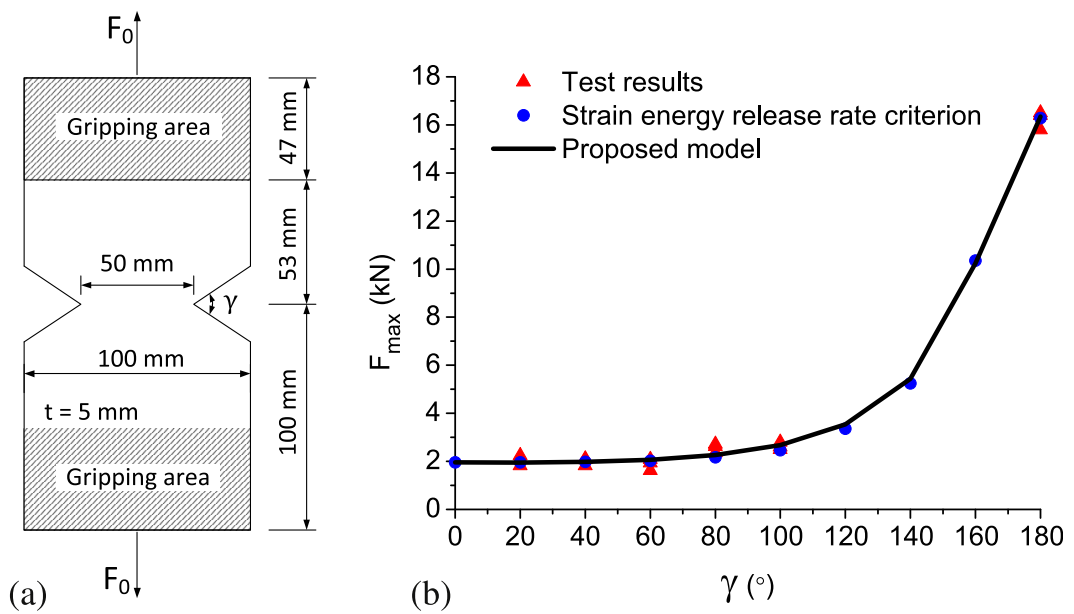

Fig. 7. (a) Failure loads $F_{\max }$ for different notch opening angles $\gamma$. (b) The model prediction is compared to the results of Refs. [6,7].

release criterion [7], which are also presented in Fig. 7b. Good agreement with the complete set of results was observed for $r=4$.

\subsubsection{Dunn's experiments}

Dunn et al. [42] performed a series of three-point bending tests on notched specimens (N-TPB) in polymethyl methacrylate (PMMA) with dimensions of $L=76.2 \mathrm{~mm}, t=12.7 \mathrm{~mm}$, and $h=17.8 \mathrm{~mm}$, as indicated in Fig. 8a. The tests were performed under plane strain conditions following the procedures outlined in ASTM E-399. The specimens were machined with three different notch opening angles $\gamma: 60^{\circ}, 90^{\circ}$, and $120^{\circ}$. For each notch opening angle, four notch depths $c$ were used: $1.78 \mathrm{~mm}, 3.56 \mathrm{~mm}, 5.33 \mathrm{~mm}$, and $7.11 \mathrm{~mm}$. This choice of dimensions resulted in notch depth to height ratios $c / h$ of

(a)

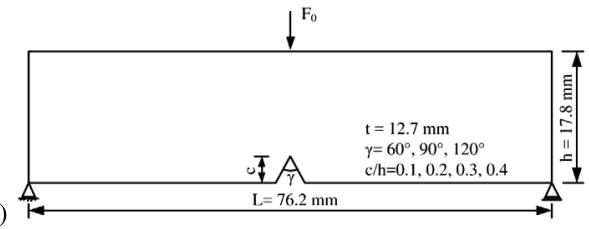

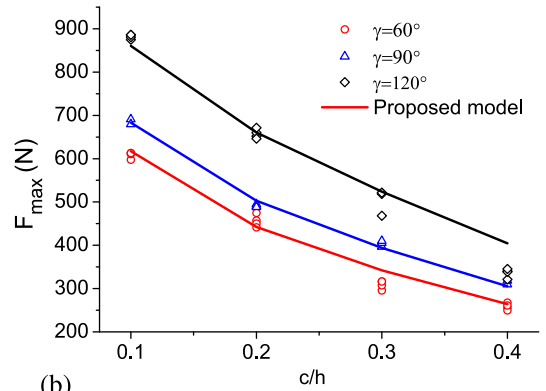

(b)

Fig. 8. (a) N-TPB specimen and (b) model predictions of the failure load $F_{\max }$ compared to the experimental results of Ref. [42] as a function of the notch to height ratio $c / h$ for various notch opening angles $\gamma$. 
$0.1,0.2,0.3$, and 0.4 , respectively. The PMMA had a Young's modulus $E=2.3 \mathrm{GPa}$, poisson ratio $v=0.36$. The average failure stress $f_{t}=124 \mathrm{MPa}$ was based on the bending tests of unnotched specimens. The fracture toughness $K_{c}=1.25 \mathrm{MPa} \sqrt{\mathrm{m}}$ adopted in the model predictions was calculated based on the relation between this quantity and the critical generalized stress intensity factor for the notch opening angle $\gamma=60^{\circ}$, as proposed by Seweryn et al. This value was expected to be more precise than the results obtained from cracked three-point bending (C-TPB) specimens $\left(K_{c}=1.02 \mathrm{MPa} \sqrt{\mathrm{m}}\right.$ with a standard deviation of $0.12 \mathrm{MPa} \sqrt{\mathrm{m}})[4]$.

The comparison between the predicted failure load $F_{\max }$ (for $r=4$ ) and the experimental data is presented in Fig. 8b for different notch opening angles $\gamma$.

\subsection{Crack initiation in a finite width plate with a circular hole}

\subsubsection{Geometry and failure mechanism}

Green et al. [43] performed open-hole tensile tests using the quasi-isotropic carbon-epoxy laminate IM7-8552 with stacking sequence $[45 / 90 /-45 / 0] 4 \mathrm{~s}$ (for laminates with a nominal thickness of $4 \mathrm{~mm}$ ). Specimens presenting the same aspect ratio based on the hole diameters $D(3.175 \mathrm{~mm}, 6.35 \mathrm{~mm}, 12.7 \mathrm{~mm}$, and $25.4 \mathrm{~mm}$ ) were adopted (for widths $w=5 D$ and lengths 20D, as shown Fig. 9a). The tensile strength $f_{t}=929 \mathrm{MPa}$ was measured in the unnotched tests, and the fracture toughness $\sqrt{G_{c} E}=42.3 \mathrm{MPa} \sqrt{\mathrm{m}}$ was estimated by Camanho et al. [15].

A post-rupture analysis showed that all specimens with the adopted stacking sequence failed due to fiber failure, which indicates that the effect of the laminate stiffness reduction caused by the progressive matrix failures on the ultimate strength of the laminate was insignificant. Hence, the rupture of these uncracked samples depended on the crack initiation and subsequent propagation thereof due to the stress concentration at the lateral edges of the holes. The failure scheme adopted in this case is presented in Fig. 9b, and is consistent with the failure pattern observed experimentally by the authors.

\subsubsection{Evaluation of $G_{0}$ and $d G_{0} / d a$}

The energy release rate corresponding to two symmetric cracks emanating from a plate with a central circular hole of radius $R$ is given by [44] for an isotropic plate as

$$
G_{0}=\frac{\sigma_{0}^{2} \pi a}{E} A_{3}^{2} A_{4}^{2},
$$

where $\sigma_{0}$ is the applied stress, $a$ is the extended crack length from the hole, and $A_{3}$ is the boundary correction factor for the circular hole. The equation for $A_{3}$ is

$$
A_{3}=1+0.358\left(\frac{R}{d}\right)+1.425\left(\frac{R}{d}\right)^{2}-1.578\left(\frac{R}{d}\right)^{3}+2.156\left(\frac{R}{d}\right)^{4}
$$

with $d=a+R$ as indicated in Fig. 9b. The quantity $A_{4}$ is the finite width correction factor and is equal to
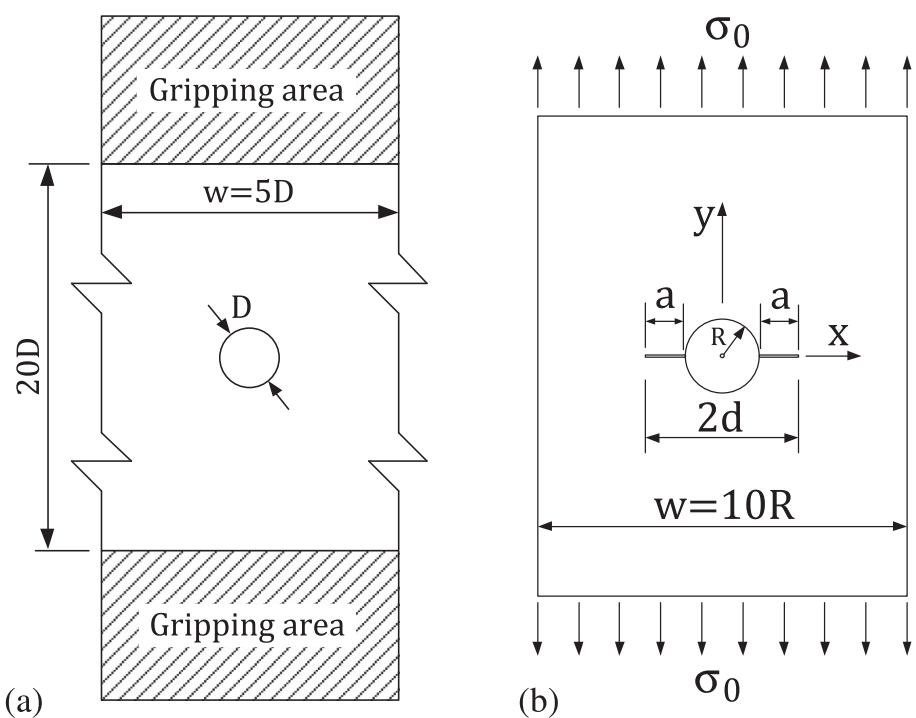

Fig. 9. (a) Geometry of the plates with circular holes (modified from the illustration by [43]), and (b) the corresponding failure mechanism (two symmetric cracks emanating from two sides of the hole). 


$$
A_{4}=\sqrt{\sec \left(\frac{\pi R}{w}\right) \sec \left(\frac{\pi d}{w}\right)} .
$$

The value of $d G / d a$ is obtained by derivation of the expression for $G$ (Eq. (11)) with respect to $a$.

\subsubsection{Failure identification}

When the hole diameter is sufficiently large, two limit failure mechanisms may be observed when considering the rupture of the plate: one associated with the material strength $(d \rightarrow R, G \rightarrow 0)$, and another associated with the fracture mechanics $(d \gg R)$. The hole induces a stress concentration of $3 \sigma_{0}$ in an infinite plate, which may be inferior to the tensile strength of the material $f_{t}$. Hence, in the absence of any cracks, the failure may occur for $\sigma_{N}=f_{t} / 3$, which defines the initiation of the crack. On the other hand, after a relatively long crack propagation, the structure may behave as a simple middle-cracked plate of crack length $2(R+a)$ and be governed solely by the fracture mechanics $\left(G \leqslant G_{c}\right)$. The transition between these two mechanisms is presented in Fig. 10a. The individual prediction of the strength mechanism $\sigma_{N}^{\text {strength }}=\sigma_{0} \sqrt{\operatorname{maxdG} / \mathrm{da} /\left(d G_{0} / d a\right)}$ tends to be almost independent of the extended crack size $a$, as is expected for a quasibrittle material, until the transition to LEFM behavior. In a finite width plate, the stress concentration induced by the hole tends to be bigger due to the reduction of the cross section of the sample. For a width to diameter ratio $w / D=5$, this value is equal to $3 \sigma_{0} \times A_{4}(a=0)=3.15 \sigma_{0}$.

For small diameters, the strength results [45,46] are affected by size effects [47]. This behavior is described by Eq. (5) as an increase in the load limit of the plate during crack initiation, following the trend of $\sigma_{N}^{\text {strength }}$ up to a maximum value before decreasing following the LEFM behavior, as shown in Fig. 10b. This apparent nonphysical behavior is probably an "artifact" due to the simplicity of Eqs. (3) and (5), and will be discussed in Section 5. Consider these size effects would theoretically prevent this increase in the sample strength. One may then predict a behavior similar to that shown in Fig. 10a for any hole size, which is a stable failure stress for small cracks, and is followed by a decrease as predicted by LEFM. However, it seems much simpler to define the failure load based on the maximum value $\sigma_{\max }=\max \sigma_{N}$ for all cases. The error associated with this simplification will be reduced in practical situations that concern relatively small crack sizes $a<a_{t}$ (e.g. $a_{t} \approx 0.5 \mathrm{~mm}$ for the laminated sample used in this example).

\subsubsection{Comparison to experimental results}

The predictions of the proposed model for $r=15$ are compared to experimental results and other model predictions in Fig. 11. The theoretical results coincide with the predictions using the average stress method given by Green et al. [43] for the failure stress $\sigma_{\max }$, as shown in Fig. 11a. For the smallest hole diameters $D(3.175 \mathrm{~mm}$ and $6.35 \mathrm{~mm})$, the failure mechanism was associated with the fiber pull-out across the width, which may explain the relative deviation of the results. It should be noted that this also happens with respect to the average stress criterion. The predictions of finite fracture mechanics given by Camanho et al. [15] also present an offset between the results of the smallest hole and the others.

Holes with bigger diameters induce a failure stress $\sigma_{\max }$ near $f_{t} / 3$, as is expected due to the stress concentration of approximately $3 \sigma_{0}$ at the edge of the holes. Fig. $11 \mathrm{~b}$ illustrates the difference between the predictions of the proposed model and the size effect law. Type 2 SEL fits well the test results, but predicts a failure stress $\sigma_{\max }$ which fades to zero for large holes. The extended size effect law $[48,49]$ corrects this trend for the holed specimens, which is also the case of the proposed model.

\section{Failure process and length scales}

The criterion represented by Eq. (5) characterizes the rupture as continuous process. It defines the crack initiation and its propagation based on energetical quantities. In some cases, such as structures presenting weak singularities (e.g. v-notches)
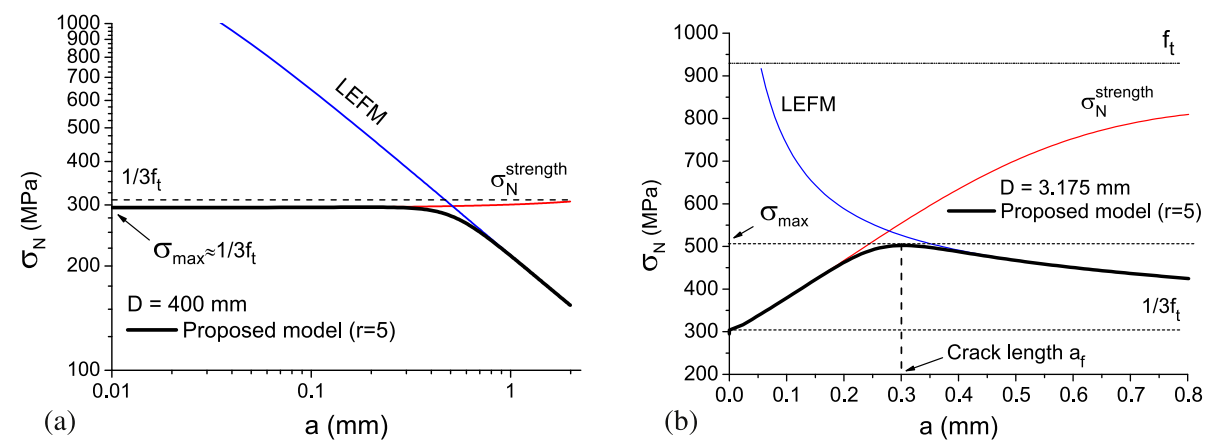

Fig. 10. Nominal strength $\sigma_{N}$ in a plate (a) with a big hole, and (b) with a small hole as function of the extended crack size $a$. 

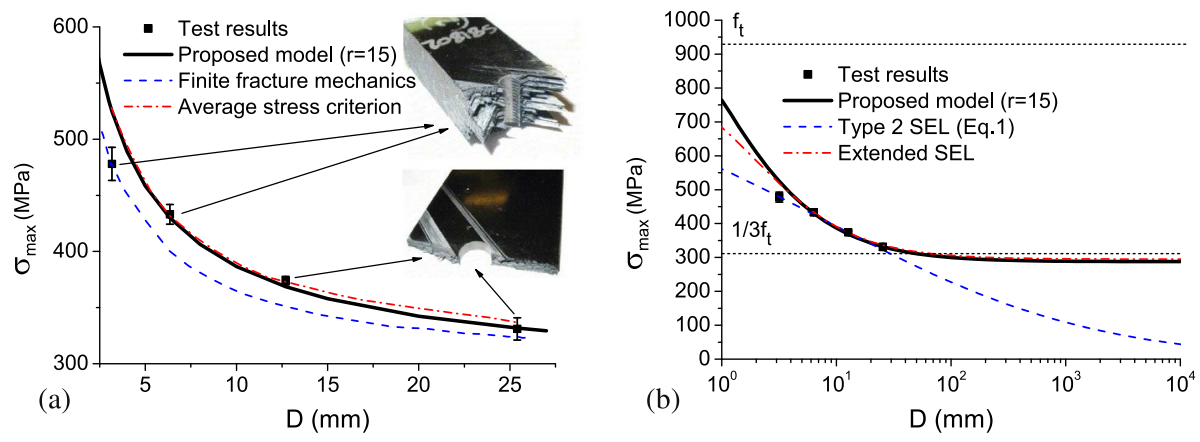

Fig. 11. Prediction of the failure stress $\sigma_{\max }$ for various hole diameters $D$ compared to the experimental [43] and model-based results. (a) Comparison between the proposed model, average stress criterion and finite fracture mechanics [15]. The insets depict the rupture patterns for different hole diameters. (b) Comparison between the proposed model and two versions of the size effect law (SEL).

or stress concentrations (e.g. holes), the maximum value of the load $F_{N}$ was obtained after a propagation length $a_{f}$. At this length scale, $F_{N}$ is maximized, which means that $a_{f}$ mathematically minimizes the quantity $\mu_{0}$ (Eq. (6)) with respect to the crack length $a$. After some algebraic work, the equation $d \mu_{0} / d a=0$ can be rewritten as

$$
\left(\frac{-\left(G_{0}\right)^{r-1}}{\left(d G_{0} / d a\right)^{r-2} d^{2} G_{0} / d a^{2}}\right)^{1 / r}=\frac{G_{c}}{\max d G / d a}=\frac{l_{c h}}{1.12^{2} \pi}
$$

where $l_{c h}=G_{c} E / f_{t}^{2}$ is the characteristic length of the material. The length $a_{f}$, solution of Eq. (14), is easily obtained for a vnotch plate $\left(a_{f}=0.254 l_{c h}(2-2 \lambda)^{1 / r}(2 \lambda-1)^{(1-1 / r)}\right)$. In Fig. 12a, the value of $a_{f} / l_{c h}$ is plotted as a function of the notch opening angle $\gamma$ for $r=4$. The ratio $a_{f} / l_{c h}$ can be obtained numerically for a finite width plate with a circular hole. In Fig. $12 \mathrm{~b}, a_{f} / l_{c h}$ is presented for different hole diameters $D(r=5$ and width $w=5 D)$.

The analysis of the length $a_{v r}=\left(-(G)^{r-1} /\left((d G / d a)^{r-2} d^{2} G / d a^{2}\right)\right)^{1 / r}$ (based on the left-hand side of Eq. (14)) can technically remedy the nonphysical increase of the failure load observed during crack initiation in v-notched (Fig. 6) or holed plates (Fig. 10). Only if $a_{v r} \geqslant l_{c h} /\left(1.12^{2} \pi\right)$, which corresponds to $a \geqslant a_{f}$, the failure load should be considered as physically consistent. Otherwise, the propagated crack $a$ would only present a mathematical meaning on the crack initiation process. Consider a finite crack length absolutely bigger than $a_{f}$ for the calculations, similar to finite fracture mechanics approaches $[12,13,15]$ can also prevent any increase on the failure load.

Despite all possible approaches to avoid this apparent problem of the increase of the failure load, it should be noted that the length scale $a_{f}$ is directly related to the characteristic length $l_{c h}$, usually associated to the size of the fracture process zone (FPZ), and the parameter $r$. The FPZ is an important element in many models [5,8,13], physically associated to a region containing micro-cracks near the crack tip. In small scales $(a \rightarrow 0)$, the size effect behavior is particular and alternative models are proposed under these conditions [50,51]. The improvement of Eq. (5) based on these effects for $a_{v r} \leqslant l_{c h} /\left(1.12^{2} \pi\right)$ may provide a finer and more realistic description of the crack initiation.
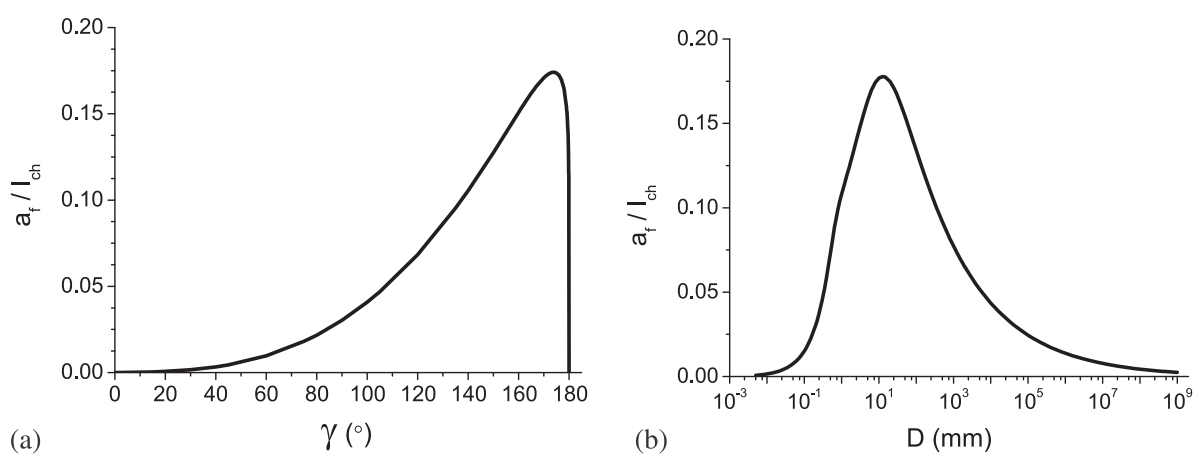

Fig. 12. Ratio $a_{f} / l_{c h}$ (a) versus notch opening angle $\gamma$ for a v-notched plate and (b) as a function of the hole diameter $D$ for a holed plate $\left(l_{c h}=2.07 \mathrm{~mm}\right)$. 


\section{Conclusions}

The local model proposed in this paper consistently reflects the main rupture trends from crack initiation to crack propagation based on its agreement with the experimental results for different geometries. In all analyzed cases, the failure was induced by an opening mode wherein the value of the energy release rate $G$ controlled the propagation of the crack, and its derivative with respect to the crack size $d G / d a$ controlled the crack initiation. The competition between these two quantities was related to the material parameters, namely, the fracture energy $G_{c}$, tensile strength $f_{t}$, and parameter $r$, which characterizes the transition between the crack initiation and propagation states. Despite the clear physical sense of $r$, only further testing with the same material and completely different geometries would definitively allow the association of this parameter exclusively to this material.

The principal feature of the model is to identify the effects of the nominal stress (a non-local quantity) through the evolution of the energy release rate $G$ (in a local sense) specifically at the initiation of the crack. This leads to an alternative description of the rupture, which allows a relatively simple analysis of structures with any size of crack, or no cracks at all. For complex geometries and/or boundary conditions, a numerical implementation of the present formulation may produce convergent results with respect to the mesh sizes, depending only on the precision of the $G$ and $d G / d a$ values. The scope of LEFM is extended to a certain extent, considering that neither plasticity nor damage is necessarily associated with the model to describe crack initiation.

Size effects caused by stress concentration (e.g. at the edges of the holes), were theoretically quantified using the value of $d G / d a$. Despite the simplicity of Eq. (5), the equation provides good insight into the competition between the failure mechanisms at a local level. Information regarding this point of view associated to the existing background may contribute to the improvement of rupture analysis.

\section{Acknowledgment}

Financial support from the program of China Scholarships Council.

\section{Appendix A. Failure mechanisms}

The crack size dependence in Eq. (3) can be rewritten by considering the notion of the energy release rate. In an elastic plate under tension (Fig. 1c), the energy release rate (in mode I) can be expressed as

$$
G=\frac{\left[A_{1}(a / w) \sigma_{N}\right]^{2} \pi a}{E}
$$

which is a fundamental quantity used to describe the propagation of cracks in fracture mechanics when compared to the material fracture energy $G_{c}$, and $A_{1}(a / w)$ is a coefficient that depends on the geometry of the element and the size of the crack $a$.

The crack length $a$ can be obtained by

$$
a=\frac{G E}{\pi\left[A_{1}(a / w) \sigma_{N}\right]^{2}} .
$$

The transition crack length $a_{t}$ can be defined based on the value of $a$ (Eq. (A.2)) when $G=G_{c}$ (fracture energy) and $\sigma_{N}=f_{t}$ (material strength):

$$
a_{t}=\frac{G_{c} E}{\pi\left[A_{1}(a / w) f_{t}\right]^{2}} .
$$

After substituting Eqs. (A.2) and (A.3) into Eq. (3) and some algebraic work, one obtains

$$
\left(\frac{\sigma_{N}}{f_{t}}\right)^{2 r}+\left(\frac{G}{G_{c}}\right)^{r}=1
$$

\section{Appendix B. Local evaluation of the nominal strength $\sigma_{N}$}

Considering an elastic plate under tension, the rate of variation of $G$ (see Eq. (A.1)) for an infinitesimal propagation of the crack da can be written as

$$
\frac{d G}{d a}=\frac{\left[A_{1}(a / w) \sigma_{N}\right]^{2} \pi}{E}+\frac{2 A_{1}(a / w) \sigma_{N} \pi}{E} \frac{d A_{1}(a / w)}{d a} a .
$$

For very small cracks ( $a \rightarrow 0$ ), the second term of Eq. (B.1) vanishes, and $d G / d a$ contains useful information about the nominal stress that is inducing $G$ : 


$$
\frac{d G}{d a}=\frac{\left[A_{1}(a / w \rightarrow 0) \sigma_{N}\right]^{2} \pi}{E},
$$

where $A_{1}(a / w \rightarrow 0)=1.12$ for an edge crack [35].

The maximum value of $d G / d a$ may be obtained for an intact plate when tested at its tensile limit $\left(\sigma_{N}=f_{t}\right)$ :

$$
\max \frac{d G}{d a}=\frac{\left[A_{1}(a / w \rightarrow 0) f_{t}\right]^{2} \pi}{E}=\frac{\left(1.12 f_{t}\right)^{2} \pi}{E} .
$$

Hence, the ratio between $d G / d a$ and its maximum value can be used to replace the ratio $\sigma_{N} / f_{t}$ in Eq. (4):

$$
\frac{d G / d a}{\max d G / d a} \approx\left(\frac{\sigma_{N}}{f_{t}}\right)^{2}
$$

\section{Appendix C. Evaluation of the energy release rate $G_{0}$ for $v$-notched samples}

The stress intensity factor $K_{0}$ corresponding to a short crack emanating from the notch tip depends on the generalized stress intensity factor $K_{0}^{N}$, notch opening angle $\gamma$, and crack length $a$ [52]. The relation between the two stress intensities and the crack length is given by [41] for cracks that are much shorter than the notch depth. Which reads

$$
K_{0}=\Lambda(\gamma) \sqrt{\pi} \frac{K_{0}^{N}}{(2 \pi)^{1-\lambda}} a^{\lambda-1 / 2},
$$

where $\Lambda$ is plotted and tabulated in [41]. It should be noted that there is a difference of $1 /(2 \pi)^{1-\lambda}$ between Eq. (C.1) and the original equation presented in [41] due to the different formal definition of generalized stress intensity factor.

The substitution of Eq. (C.1) into the well-known Irwin's relation in plane stress $\left(E^{*}=E\right)$ and plane strain $\left(E^{*}=E /\left(1-v^{2}\right)\right)$ yields:

$$
G_{0}=\eta \frac{\left(K_{0}^{N}\right)^{2}}{E^{*}} a^{2 \lambda-1}
$$

for $\eta=\Lambda^{2}(\gamma) \pi /(2 \pi)^{2-2 \lambda}$, calculated based on the highly accurate $\Lambda$ values given by Philipps et al. [41] for the mode I case. The generalized stress intensity factor $K_{0}^{N}$ is related to the remote loading $F_{0}$ by $K_{0}^{N}=\xi F_{0}$, where the coefficient $\xi$ for different specimens can be obtained numerically. The values of $\xi$ for v-notched plates with different notch opening angles $\gamma$ are tabulated in [7]. For v-notched beams, $\xi$ values are calculated from the values of $K_{c}^{N} /(2 \pi)^{1-\lambda}$ and $\sigma_{\max }$ tabulated in [42] $\left(\xi=K_{c}^{N} /\left[\sigma_{\max } 2 h^{2} t /(3 L)\right]\right.$, where $h, t$, and $L$ are the height, thickness, and spam of the beams, respectively).

Table C.1 presents the values of $\lambda, \xi, \Lambda$ and $\eta$ for different notch opening angles for v-notched plates and beams.

Table C.1

Parameters $\lambda, \xi, \Lambda$ and $\eta$ for v-notched plates and beams. The values with * were not originally tabulated but have been calculated by linear interpolation.

\begin{tabular}{ccccc}
\hline$\gamma$ & $\lambda[7,42,53]$ & $\xi$ of plates $\left(\mathrm{Pa} \mathrm{m}^{1-\lambda} / \mathrm{N}\right)[7]$ & $\xi$ of beams $\left(\mathrm{Pa} \mathrm{m}^{1-\lambda} / \mathrm{N}\right)[42]$ & $\Lambda[41]$ \\
\hline 0 & 0.5 & 613.3 & n/a & 1.414 \\
20 & 0.5004 & 616.6 & n/a & $1.417^{*}$ \\
30 & 0.5015 & n/a & n/a & 1.000 \\
40 & 0.5035 & 632.3 & n/a & 1.005 \\
60 & 0.5122 & 667.3 & 2335.5 & $1.414^{*}$ \\
80 & 0.5304 & 735.0 & n/a & 1.011 \\
90 & 0.5445 & n/a & 2964.6 & 1.013 \\
100 & 0.5628 & 853.7 & n/a & $1.389^{*}$ \\
120 & 0.6157 & 1057.6 & 4703.8 & 1.380 \\
140 & 0.6972 & 1424.6 & n/a & $1.362^{*}$ \\
150 & 0.7520 & n/a & n/a & 1.121 \\
160 & 0.8187 & 2153.5 & n/a & 1.168 \\
180 & 1 & 6314.6 & n/a & $1.270^{*}$ \\
\hline
\end{tabular}

\section{References}

[1] Neuber H. Theory of notch stresses: principles for exact calculation of strength with reference to structural form and material. 2nd ed. Berlin: Springer Verlag; 1958.

[2] Peterson RE. Notch sensitivity. In: Metal fatigue. New York: McGraw-Hill; 1959. p. 293-306.

[3] Novozhilov VV. On a necessary and sufficient criterion for brittle strength. J Appl Math Mech 1969;33(2):201-10.

[4] Seweryn A. Brittle fracture criterion for structures with sharp notches. Eng Fract Mech 1994;47(5):673-81. 
[5] Seweryn A, Mróz Z. A non-local stress failure condition for structural elements under multiaxial loading. Eng Fract Mech 1995;51(6):955-73.

[6] Seweryn A, Poskrobko S, Mróz Z. Brittle fracture in plane elements with sharp notches under mixed-mode loading. J Eng Mech 1997;123(6):535-43.

[7] Seweryn A, Łukaszewicz A. Verification of brittle fracture criteria for elements with V-shaped notches. Eng Fract Mech 2002;69(13):1487-510.

[8] Leguillon D. Strength or toughness? A criterion for crack onset at a notch. Eur J Mech - A/Solids 2002;21(1):61-72.

[9] Yosibash Z, Bussiba A, Gilad I. Failure criteria for brittle elastic materials. Int J Fract 2004;125(3):307-33.

[10] Leguillon D, Yosibash Z. Crack onset at a V-notch. Influence of the notch tip radius. Int J Fract 2003;122(1):1-21.

[11] Yosibash Z, Priel E, Leguillon D. A failure criterion for brittle elastic materials under mixed-mode loading. Int J Fract 2006;141(1):291-312.

[12] Weißgraeber P, Leguillon D, Becker W. A review of finite fracture mechanics: crack initiation at singular and non-singular stress raisers. Arch Appl Mech 2016;86(1):375-401.

[13] Cornetti P, Pugno N, Carpinteri A, Taylor D. Finite fracture mechanics: a coupled stress and energy failure criterion. Eng Fract Mech 2006;73 (14):2021-33.

[14] Carpinteri A, Cornetti P, Pugno N, Sapora A, Taylor D. A finite fracture mechanics approach to structures with sharp V-notches. Eng Fract Mech 2008;75 (7):1736-52.

[15] Camanho PP, Erçin GH, Catalanotti G, Mahdi S, Linde P. A finite fracture mechanics model for the prediction of the open-hole strength of composite laminates. Compos Part A: Appl Sci Manuf 2012;43(8):1219-25.

[16] Weißgraeber P, Felger J, Geipel D, Becker W. Cracks at elliptical holes: stress intensity factor and finite fracture mechanics solution. Eur J Mech - A/ Solids 2016;55:192-8.

[17] Barenblatt GI. The formation of equilibrium cracks during brittle fracture. General ideas and hypotheses. Axially-symmetric cracks. J Appl Math Mech 1959;23(3):622-36.

[18] Barenblatt GI, Salganik RL, Cherepanov GP. On the nonsteady motion of cracks. PMM Appl Math Mech 1962;26:469-77.

[19] Dugdale DS. Yielding of steel sheets containing slits. J Mech Phys Solids 1960;8(2):100-4.

[20] Song SH, Paulino GH, Buttlar WG. Simulation of crack propagation in asphalt concrete using an intrinsic cohesive zone model. J Eng Mech 2006;132 (11):1215-23.

[21] Carpinteri A, Cornetti P, Barpi F, Valente S. Cohesive crack model description of ductile to brittle size-scale transition: dimensional analysis vs. renormalization group theory. Eng Fract Mech 2003;70(14):1809-39.

[22] Irwin GR. Analysis of stresses and strains near the end of a crack traversing a plate. J Appl Mech 1957;24:361-4.

[23] Taylor D. The theory of critical distances: a new perspective in fracture mechanics. Elsevier; 2007.

[24] Cundall PA, Strack OD. A discrete numerical model for granular assemblies. Géotechnique 1979;29(1):47-65.

[25] Meguro K, Hakuno M. Fracture analyses of concrete structures by the modified distinct element method. Struct Eng/Earthq Eng 1989;6(2):283-94.

[26] Matsuda Y, Iwase Y. Numerical simulation of rock fracture using three-dimensional extended discrete element method. Earth Planets Space 2002;54 (4):367-78.

[27] Potyondy DO, Cundall PA. A bonded-particle model for rock. Int J Rock Mech Min Sci 2004;41(8):1329-64.

[28] Le BD, Koval G, Chazallon C. Discrete element approach in brittle fracture mechanics. Eng Comput 2013;30(2):263-76,

[29] Le BD, Koval G, Chazallon C. Discrete element model for crack propagation in brittle materials. Int J Numer Anal Methods Geomech 2016;40(4):583-95.

[30] Koval G, Le BD, Chazallon C. Discrete element model for quasi-brittle rupture under tensile and compressive loading. Int J Numer Anal Methods Geomech 2016;40(17):2339-52.

[31] Bažant ZP. Size effect in blunt fracture: concrete, rock, metal. J Eng Mech 1984;110(4):518-35.

[32] Bažant ZP. Probabilistic modeling of quasibrittle fracture and size effect. In: Proc, 8th int conf on structural safety and reliability (ICOSSAR), Swets and Zeitinger, Balkema; 2001. p. 1-23.

[33] Hu X, Wittmann F. Size effect on toughness induced by crack close to free surface. Eng Fract Mech 2000;65(2-3):209-21.

[34] Hu X. An asymptotic approach to size effect on fracture toughness and fracture energy of composites. Eng Fract Mech 2002;69(5):555-64.

[35] Duan K, Hu X, Wittmann FH. Scaling of quasi-brittle fracture: boundary and size effect. Mech Mater 2006;38(1-2):128-41.

[36] Tada H, Paris PC, Irwin GR. The stress analysis of cracks handbook. Wiley; 2000.

[37] Birchall JD, Howard AJ, Kendall K. Flexural strength and porosity of cements. Nature 1981;289(5796):388-90.

[38] Karihaloo BL, Abdalla HM, Xiao QZ. Size effect in concrete beams. Eng Fract Mech 2003;70(7-8):979-93.

[39] Yu Q, Le J, Hoover CG, Bažant ZP. Problems with Hu-Duan boundary effect model and its comparison to size-shape effect law for quasi-brittle fracture. J Eng Mech 2009;136(1):40-50.

[40] Higgins DD, Bailey JE. Fracture measurements on cement paste. J Mater Sci 1976;11(11):1995-2003.

[41] Philipps AG, Karuppanan S, Churchman CM, Hills DA. Crack tip stress intensity factors for a crack emanating from a sharp notch. Eng Fract Mech 2008;75(18):5134-9.

[42] Dunn ML, Suwito W, Cunningham S. Fracture initiation at sharp notches: correlation using critical stress intensities. Int J Solids Struct 1997;34 (29):3873-83.

[43] Green BG, Wisnom MR, Hallett SR. An experimental investigation into the tensile strength scaling of notched composites. Compos Part A: Appl Sci Manuf 2007;38(3):867-78.

[44] Newman JC. A nonlinear fracture mechanics approach to the growth of small cracks. Technical report. DTIC document; 1983.

[45] Lajtai EZ. Effect of tensile stress gradient on brittle fracture initiation, vol. 9; 1972. p. 569-78.

[46] Carter BJ. Size and stress gradient effects on fracture around cavities. Rock Mech Rock Eng 1992;25(3):167-86.

[47] Wisnom MR, Hallett SR, Soutis C. Scaling effects in notched composites. J Compos Mater 2010;44(2):195-210.

[48] Bažant ZP. Asymptotic matching analysis of scaling of structural failure due to softening hinges. I: Theory. J Eng Mech 2003;129(6):641-50.

[49] Maimí P, González EV, Gascons N, Ripoll L. Size effect law and critical distance theories to predict the nominal strength of quasibrittle structures. Appl Mech Rev 2013;65(2):1-16.

[50] Bažant ZP, Li Z. Zero-brittleness size-effect method for one-size fracture test of concrete. J Eng Mech 1996;122(5):458-68.

[51] Bažant ZP, Yu Q. Universal size effect law and effect of crack depth on quasi-brittle structure strength. J Eng Mech 2009;135(2):78-84.

[52] Cornetti P, Sapora A, Carpinteri A. Mode mixity and size effect in V-notched structures. Int J Solids Struct 2013;50(10):1562-82.

[53] Carpinteri A, Cornetti P, Pugno N, Sapora A. On the most dangerous V-notch. Int J Solids Struct 2010;47(7-8):887-93. 